\title{
Study of insulin resistance, inflammatory cytokines and adhesive molecules in obese subjects with obstructive sleep apnea
}

\begin{abstract}
Background: Obstructive sleep apnea (OSA) is recognized as a major public health issue, as it has a significant influence on the incidence and prognosis of cardiovascular diseases.

Objective: This study was designed to detect the association between OSA and biomarkers of inflammation and adhesion molecules that may be useful in medical screening for OSA.

Methods: Sixty-five volunteer subjects were interviewed. However, only 64 of them met eligibility criteria. Their age ranged from 28-53 years and their body mass index (BMI) ranged from 30 to $40 \mathrm{~kg} / \mathrm{m}^{2}$. All participants who were enrolled into two groups according to value of Apnea-hypopnea index (AHI) into two groups: Group (A) consisted of 27 obese subjects with $\mathrm{AHI} \geq 5$ events/hour and group (B) consisted of 38 obese subjects with AHI $<5$ events/hour.

Results: The mean values of Tumor necrosis factor -alpha (TNF- $\alpha$ ), Interleukin-6 (IL-6), C-reactive protein (CRP), Apnea-hypopnea index (AHI), Oxygen desaturation index (ODI), glucose, insulin, Homeostasis Model Assessment-Insulin Resistance Index (HOMA-IR), Inter-Cellular Adhesion Molecule (ICAM-1), Vascular Cell Adhesion Molecule (VCAM1) and E-selectin were significantly higher in group (A) than in group (B). However, the AHI and ODI showed a strong direct relationship with TNF- $\alpha$, Il-6, CRP, glucose, insulin, HOMA-IR, ICAM-1,VCAM-1 and E-selectin in group (A).
\end{abstract}

Conclusion: Obese subjects with OSA are associated with systemic inflammation, insulin resistance and elevated values of adhesive molecules.

Keywords: obstructive sleep apnea, obesity, adhesive molecules, cytokines, insulin resistance
Volume 7 Issue 2 - 2017

\author{
Essam $\mathrm{H}$ Jiffri \\ Department of Medical Laboratory Technology, King Abdulaziz \\ University, Saudi Arabia
}

Correspondence: Essam H Jiffri, Department of Medical Laboratory Technology, Faculty of Applied Medical Sciences, King Abdulaziz University, P.O. Box 80324, Jeddah, 21589 , Saudi Arabia, Email ejiff@hotmail.com

Received: May 04, 2017| Published: July 07, 2017

\section{Introduction}

Obstructive sleep apnea is common and affects 2 to $26 \%$ in women and 4 to $49 \%$ in men worldwide. ${ }^{1}$ Several factors have been proposed to address these sex-differences, such as upper airway anatomy, fat distribution and testosterone levels. ${ }^{2}$ Diagnosis of OSA is made when AHI is $>5$ events/hour of sleep and OSA severity is classified upon AHI value into mild ( $>5$ and $<15$ events/hour), moderate $(\geq 15$ and $\leq 30$ events/hour) and severe ( $>30$ events/hour). ${ }^{3}$ However, OSA is a modifiable CVD risk factor. ${ }^{4}$

Obstructive sleep apnea is closely associated to obesity ${ }^{5}$ and systemic inflammation and oxidative stress markers are closely related to incidence of cardiovascular diseases. ${ }^{6,7}$ In addition, there is an association between increased risk of cardiovascular disorders and OSA. ${ }^{8-11}$

Abnormal levels of inflammatory cytokines include C-reactive protein (CRP), interleukin-6 (IL-6), interleukin-8 (IL-8), and tumor necrosis factor a (TNF- $\alpha)$ in obesity are related to increased cardiovascular risk. ${ }^{12-14}$ In addition, increased levels of adhesive molecules include intercellular adhesion molecule-1 (ICAM-1) and vascular cell adhesion molecule-1 (VCAM-1), E-selectin and P-selectin are associated with cardiovascular disease and obesity. ${ }^{15,16}$

The aim of this study was to detect the association between OSA and biomarkers of inflammation and adhesion molecules that may be useful in medical screening for OSA.

\section{Patients and methods}

\section{Subjects}

Sixty-five volunteer subjects were interviewed; only 64 of them met eligibility criteria, signed the consent form to participate in the study and completed the detailed evaluation at the Sleep Unit of the Internal Medicine Department at King Abdul Aziz University Hospital. Participants were enrolled between May 2016 and September 2016. Scientific research ethical committee of the Faculty of Applied Medical Sciences, King Abdulaziz University approved this study. Their age ranged from 28-53 years and their body mass index (BMI) ranged from 30 to $40 \mathrm{~kg} / \mathrm{m}^{2}$. While, the exclusion criteria were pregnant women, liver disease, smoking, diabetes mellitus, renal disease, respiratory infection, endocrine disease, thyroid diseases, patients with body mass index $\geq 40 \mathrm{~kg} / \mathrm{m}^{2}$ and subjects taking any medications or herbal supplements. A cardiologist conducted an initial clinical examination for all participants who were enrolled into two groups according to value of AHI into two groups: Group (A) consisted of 27 obese subjects with AHI $\geq 5$ events/hour and group (B) consisted of 38 obese subjects with AHI $<5$ events/hour.

\section{Measurements}

For all subjects, independent assessors who were blinded to group assignment and not involved in the routine treatment of the patients performed clinical evaluations and laboratory analysis. Body mass index (BMI) was calculated on the basis of weight (kilograms) and 
height (meters), and subjects were classified as normal weight (BMI 18.5-24.9 $\mathrm{kg} / \mathrm{m}^{2}$ ), overweight (BMI 25-29.9 $\mathrm{kg} / \mathrm{m}^{2}$ ), and obese $\left(\mathrm{BMI} \geq 30 \mathrm{~kg} / \mathrm{m}^{2}\right)$. In addition, between 07:30 and 09:00, after an overnight fast of $12 \mathrm{~h}$ fasting blood sample was drawn. Plasma glucose concentration and insulin were determined (Roche Diagnostics $\mathrm{GmbH}$, Mannheim, Germany) using commercially available assay kits. Insulin resistance was assessed by homeostasis model assessment (HOMA-IR). HOMA-IR = [fasting blood glucose $(\mathrm{mmol} / \mathrm{l})$ - fasting insulin $(\mathrm{mIU} / \mathrm{ml})] / 22.5 .^{17}$

Sleep recordings and daytime sleepiness (Polysomnography): Embletta system (Flaga, Reykjavik, Iceland) of the Sleep Unit of the Internal Medicine Department at King Abdul Aziz University Hospital was the polysomnography that was used as sleep recording system. Finger pulse oximetry was used to have recordings of oxygen saturation continuously overnight. Both apnea and hypopnea were recorded to calculate apnea hypoapnea index (AHI). In addition, the number of dips $4 \%$ of basal $\mathrm{SaO} 2 \%$ /hour (oxygen desaturation index [ODI]) was measured. ${ }^{18}$

Measurement of biomarkers of endothelial function: Biomarkers of endothelial function includes inter-cellular adhesion molecule (ICAM-1), vascular cell adhesion molecule (VCAM-1) and E-selectin that were measured from frozen serum samples stored at $-80^{\circ} \mathrm{C}$. Enzyme-linked immunosorbent assays (ELISAs) were used to measure soluble levels of E-selectin, ICAM-1 and VCAM-1 (R\&D Systems, France).

Measurement of inflammatory cytokines: Venous blood samples after a 12-hours fasting were centrifuged at $+4{ }^{\circ} \mathrm{C}(1000=\mathrm{g}$ for 10 min). Interleukin-6 (IL-6) levels were analyzed by "Immulite 2000 " immunassay analyzer (Siemens Healthcare Diagnostics, Deerfield,
USA). However, tumor necrosis factor-alpha (TNF- $\alpha$ ) and C-reactive protein (CRP) levels were measured by ELISA kits (ELX 50) in addition to ELISA microplate reader (ELX 808; BioTek Instruments, USA).

\section{Statistical analysis}

Independent " $\mathrm{t}$ " test was used to compare the investigated parameters between both groups $(\mathrm{P}<0.05)$. However, the degree of correlation between AHI, ODI,TNF- $\alpha$, Il- 6 , CRP, glucose, insulin, HOMA-IR, ICAM-1,VCAM-1 and E-selectin was calculated with Pearson's correlation coefficients (r).

\section{Results}

Detailed baseline characteristics of all participants were presented in Table 1. There was no significant difference for all characteristics in both groups (Table 1).

The mean values of TNF- $\alpha$, IL-6, CRP, AHI,ODI, glucose, insulin, HOMA-IR, ICAM-1, VCAM-1 and E-selectin were significantly higher in group (A) than in group (B) (Table 2). However, the AHI and ODI showed a strong direct relationship with TNF- $\alpha$, Il- 6, CRP, glucose, insulin, HOMA-IR, ICAM-1,VCAM-1 and E-selectin in group (A) (Table 3) $(\mathrm{P}<0.05)$.

BMI: Body Mass Index; TNF- $\alpha$ : Tumor Necrosis Factor -Alpha; IL-6: Interleukin-6; CRP: C-Reactive Protein; AHI: Apnea-Hypopnea Index; ODI: Oxygen Desaturation Index; HOMA-IR: Homeostasis Model Assessment-Insulin Resistance Index; ICAM-1:Inter-Cellular Adhesion Molecule; VCAM-1: Vascular Cell Adhesion Molecule; (*) indicates a significant difference, $\mathrm{P}<0.05$.

Table I Characteristics of all participants according to OSA diagnosis

\begin{tabular}{llll}
\hline & Group $(\mathbf{A})(\mathbf{n o}=\mathbf{2 7})$ & Group $(\mathbf{B})(\mathbf{n o = 3 8})$ & Significance \\
\hline Age (year) & $42.75 \pm 4.32$ & $44.6 \mathrm{I} \pm 4.28$ & $\mathrm{P}>0.05$ \\
Gender (male/female) & $20 / 17$ & $23 / 15$ & $\mathrm{P}>0.05$ \\
BMI $(\mathrm{kg} / \mathrm{m} 2)$ & $35.74 \pm 2.8 \mathrm{I}$ & $35.65 \pm 3.16$ & $\mathrm{P}>0.05$ \\
Neck circumference $(\mathrm{cm})$ & $41.21 \pm 3.2 \mathrm{I}$ & $39.88 \pm 2.72$ & $\mathrm{P}>0.05$ \\
Waist circumference $(\mathrm{cm})$ & $110.35 \pm 9.37$ & $108.92 \pm 9.25$ & $\mathrm{P}>0.05$ \\
Waist-to-hip ratio & $0.92 \pm 0.05$ & $0.84 \pm 0.04$ & $\mathrm{P}>0.05$ \\
SBP $(\mathrm{mmHg})$ & $133.16 \pm 9.18$ & $130.14 \pm 8.95$ & $\mathrm{P}>0.05$ \\
DBP $(\mathrm{mmHg})$ & $86.83 \pm 5.47$ & $84.26 \pm 5.13$ & $\mathrm{P}>0.05$ \\
\hline
\end{tabular}

BMI, body mass index; SBP, systolic blood pressure; DBP, diastolic blood pressure; HBA Ic, glycosylated haemoglobin

Table 2 The mean value and the significance values of different parameters in both groups

\begin{tabular}{|c|c|c|c|c|}
\hline & Mean +SD Group (A) $(n o=27)$ & Group(B) $(\mathrm{no}=38)$ & T-Value & Significance \\
\hline IL-6 (pg/mL) & $2.58 \pm 0.96$ & $1.87 \pm 0.88^{*}$ & 5.75 & $P<0.05$ \\
\hline CRP (pg/mL) & $4.37 \pm 1.25$ & $2.43 \pm 0.94 *$ & 5.17 & $P<0.05$ \\
\hline $\begin{array}{l}\text { Apnea Hypopnea Index } \\
\text { (events/h) }\end{array}$ & $20.76 \pm 3.58$ & $2.7 I \pm 0.43$ & 6.25 & $P<0.05$ \\
\hline $\begin{array}{l}\text { Oxygen Desaturation } \\
\text { index (events/h) }\end{array}$ & $12.78 \pm 3.27$ & $0.91 \pm 0.17$ & 6.22 & $P<0.05$ \\
\hline Glucose (mg/dL) & $91.73 \pm 5.16$ & $80.15 \pm 3.12$ & 7.18 & $P<0.05$ \\
\hline
\end{tabular}


Table Continued...

\begin{tabular}{lllll}
\hline & Mean + SD Group $(\mathbf{A})(\mathbf{n o = 2 7})$ & Group(B) $(\mathbf{n o = 3 8})$ & T-Value & Significance \\
\hline Insulin $(\mathrm{mU} / \mathrm{mL})$ & $13.8 I \pm 1.43$ & $10.29 \pm 1.16$ & 6.31 & $\mathrm{P}<0.05$ \\
HOMA-IR & $3.72 \pm 0.68$ & $2.48 \pm 0.32$ & 5.34 & $\mathrm{P}<0.05$ \\
ICAM-I $(\mathrm{ng} / \mathrm{ml})$ & $94.17 \pm 9.26$ & $80.75 \pm 7.4 I^{*}$ & 8.23 & $\mathrm{P}<0.05$ \\
VCAM-I $(\mathrm{ng} / \mathrm{ml})$ & $811.45 \pm 28.42$ & $728.21 \pm 23.19 *$ & 12.18 & $\mathrm{P}<0.05$ \\
E-selectin $(\mathrm{ng} / \mathrm{ml})$ & $16.87 \pm 3.57$ & $10.14 \pm 2.82^{*}$ & 6.14 & $P<0.05$ \\
\hline
\end{tabular}

Table 3 Correlation coefficient ( $r$ ) of AHI, ODI, TNF- $\alpha$, II-6, CRP, glucose, insulin, HOMA-IR, ICAM-I,VCAM-I and E-selectin in group (A)

\begin{tabular}{lll}
\hline & Apnea Hypopnea Index (events/h) & Oxygen desaturation Index (events/h) \\
\hline TNF- $\alpha(\mathrm{pg} / \mathrm{mL})$ & $0.625^{*}$ & $0.743^{* *}$ \\
$\mathrm{IL}-6(\mathrm{pg} / \mathrm{mL})$ & $0.712^{* *}$ & $0.522^{*}$ \\
CRP $(\mathrm{pg} / \mathrm{mL})$ & $0.618^{* *}$ & $0.547^{*}$ \\
Glucose $(\mathrm{mg} / \mathrm{dL})$ & $0.524^{*}$ & $0.646^{* *}$ \\
Insulin $(\mathrm{mU} / \mathrm{mL})$ & $0.512^{* *}$ & $0.61 I^{* *}$ \\
HOMA-IR & $0.57 I^{*}$ & $0.719^{* *}$ \\
ICAM-I $(\mathrm{ng} / \mathrm{ml})$ & $0.514^{*}$ & $0.657^{* *}$ \\
VCAM-I $(\mathrm{ng} / \mathrm{ml})$ & $0.723^{* *}$ & $0.642^{* *}$ \\
E-selectin $(\mathrm{ng} / \mathrm{ml})$ & $0.517^{*}$ & $0.618^{*}$ \\
\hline
\end{tabular}

Spearman's correlation was used $*: \mathrm{P}<0.05 * *: \mathrm{P}<0.0$ I

\section{Discussion}

Circulating abnormal levels of inflammatory markers and adhesive molecules have been associated with future cardiovascular risk. ${ }^{19,20}$ However, high risk of mortality and cardiovascular morbidity is associated with OSA. ${ }^{21,23}$ The principal findings of this study were that participants with OSA exhibited higher values of AHI,ODI,TNF$\alpha$, Il-6, CRP, glucose, insulin, HOMA-IR, ICAM-1,VCAM-1 and E-selectin compared with those without OSA. However, in correlation analysis, AHI and ODI were positively and significantly associated with TNF- $\alpha$, Il-6, CRP, glucose, insulin, HOMA-IR, ICAM-1, VCAM-1 and E- selectin, these findings are in line with many previous researches.

Concerning inflammatory markers, the results of the present study showed significantly higher values of TNF- $\alpha$, Il- 6 and CRP in group (A) than in group (B). In correlation analysis, TNF- $\alpha$, Il-6 and CRP were significantly and directly associated with the AHI and ODI. Our findings are similar to many case-controlled researches demonstrated increased level of TNF- $\alpha$ in patient with OSA in comparison to controls, along with significant reduction in TNF- $\alpha$ value with CPAP therapy. ${ }^{24,26}$ Further studies proved that TNF- $\alpha$ level was increased in OSA..$^{27,29}$ In addition, Dyugovskaya et $a .^{30}$ stated that T- lymphocytes expressed isolated higher levels of TNF- $\alpha$ than control cells in OSA patients. ${ }^{30}$ However, Ohga et al. ${ }^{31}$ \& Ryan et al..$^{32}$ reported that both TNF- $\alpha$ and IL-8 increased in patients with OSAS which were reduced following CPAP. ${ }^{31,32}$ Similarly, Devouassoux et al. ${ }^{33}$ proved that OSAS led to excessive airway expression of IL- 8 that potentially increased bronchial hyper-responsiveness in OSA subjects. ${ }^{33}$ In addition, several studies found positive associations between IL-6 levels and OSA. ${ }^{34-36}$ Moreover, Montesi et al. ${ }^{37}$ reported that the levels of the inflammatory markers include CRP), IL-8, TNF- $\alpha$ and IL-6 were higher in OSA patients. ${ }^{37}$ However, Reyad et al. ${ }^{38}$ reported that there was a statistical positive correlation between TNF- $\alpha$ and AHI that measure the severity of OSA. ${ }^{38}$ Similarly, Minoguchi et al. ${ }^{39}$ stated that levels of IL-6 and IL-18 are greater in OSA patients than controls which are correlated with severity of OSA. ${ }^{39}$ In addition, Yokoe et al. ${ }^{40}$ mentioned that among 22 subjects with OSA, where the magnitude of CRP elevation was directly related to $\mathrm{AHI}$ in these patients. ${ }^{40}$

Regarding the values of adhesive molecules, the results of the present study showed significantly higher values of ICAM-1, VCAM1 and E-selectin in in group (A) than in group (B). In correlation analysis, ICAM-1, VCAM-1 and E-selectin were significantly and directly associated with the AHI and ODI. Our findings agreed with Zamarrón-Sanz [41] reported that adhesive molecules were higher among 41 patients with OSA 82 male subjects than control group with the same sample size. ${ }^{41}$ In addition, Korzh et al ${ }^{42}$ stated that the levels of VCAM-1, E-selectin, P-selectin, CRP, WBC count were higher in OSA patients than in control subjects..$^{42}$ Similarly, several studies found direct significant relationship between adhesive molecules and severity of OSA measured by ODI and AHI. ${ }^{43-46}$

Finally, results of the present study found significantly higher values of serum insulin, glucose and HOMA-IR in group (A) than in group (B). Moreover, OSA severity measured with AHI and ODI were directly and significant associated with insulin resistance, our results agreed with Ip et al. ${ }^{47}$ reported similar findings. ${ }^{47}$ However, Fleming et al. ${ }^{48}$ reported that 73 male subjects were enrolled; 26 had moderate/ severe OSA and concluded that elevated HbA1c, CRP have an even greater association with OSA severity. ${ }^{48}$ Moreover, Araújo Lda et al. ${ }^{10}$ conducted a cross-sectional study included 53 obese adults and reported that values of glucose, neck circumference and CRP were higher in OSA patients than control group, and in addition, insulin, neck circumference and HOMA-IR were positively and significantly associated with ODI in patients with OSA. ${ }^{10}$

\section{Conclusion}

The present study suggests that in obese subjects with OSA are associated with systemic inflammation, insulin resistance and elevated values of adhesive molecules. 


\section{Acknowledgments}

The author thanks Prof. Mohammed Tayeb for his skillful assistance in selection of participants, laboratory analysis and during clamp procedures of this study. In addition, author is grateful for the cooperation and support of all patients who participated in this study.

\section{Conflicts of interest}

The authors declare there are no conflicts of interest related to the article.

\section{Funding}

None.

\section{References}

1. Heinzer R, Vat S, Marques-Vidal P, et al. Prevalence of sleep-disordered breathing in the general population: the HypnoLaus study. Lancet Respir Med. 2015;3(4):310-318.

2. Wittert G. The relationship between sleep disorders and testosterone in men. Asian J Androl. 2014;16(2):262-265.

3. Parati G, Lombardi C, Hedner J, et al. Recommendations for the management of patients with obstructive sleep apnoea and hypertension. Eur Respir J. 2013;41(3):523-538.

4. Javaheri S, Barbe F, Campos-Rodriguez F, et al. Sleep Apnea: Types, Mechanisms, and Clinical Cardiovascular Consequences. J Am Coll Cardiol. 2017;69(7):841-858.

5. Young T, Palta M, Dempsey J, et al. The occurrence of sleep-disordered breathing among middle-aged adults. The New England journal of medicine. 1993;328(17):1230-1235.

6. Arnardottir ES, Mackiewicz M, Gislason T, et al. Molecular signatures of obstructive sleep apnea in adults: a review and perspective. Sleep. 2009;32(4):447-470.

7. Hajer GR, van Haeften TW, Visseren FL. Adipose tissue dysfunction in obesity, diabetes, and vascular diseases. European heart journal. 2008;29(24):2959-2971.

8. Drager LF, Togeiro SM, Polotsky VY, et al.Obstructive sleep apnea. A cardiometabolic risk in obesity and the metabolic syndrome. J Am Coll Cardiol. 2013;62(7):569-576.

9. Loke YK, Brown JW, Kwok CS, et al. Association of obstructive sleep apnea with risk of serious cardiovascular events a systematic review and meta-analysis. Circ Cardiovasc Qual Outcomes. 2012;5(5):720-728.

10. Araújo Lda S, Fernandes JF, Klein MR, et al. Obstructive sleep apnea is independently associated with inflammation and insulin resistance, but not with blood pressure, plasma catecholamines, and endothelial function in obese subjects. Nutrition. 2015;31(11-12):1351-1357.

11. Ali SS, Oni ET, Warraich HJ, et al.Systematic review on noninvasive assessment of subclinical cardiovascular disease in obstructive sleep apnea: new kid on the block. Sleep Med Rev. 2014;18(5):379-391.

12. Gopalakrishnan P, Tak T. Obstructive sleep apnea and cardiovascular disease. Cardiol Rev. 2011;19(6):279-290.

13. Almendros I, Farre R, Torres M, et al. Early and mid-term effects of obstructive apneas in myocardial injury and inflammation. Sleep Med. 2011;12(10):1037-1040.

14. Montesi S, Bajwa E, Malhotra A. Biomarkers of sleep apnea. Chest. 2012;142(1):239-245

15. Pak VM, Keenan BT, Jackson N, et al. Adhesion molecule increases in sleep apnea: beneficial effect of positive airway pressure and moderation by obesity. Int J Obes (Lond). 2015;39(3):472-479.
16. Pak VM, Grandner MA, Pack AI. Circulating adhesion molecules in sleep apnea and cardiovascular disease. Sleep Med Rev. 2014;18(1):25-

17. Matthews DR, Hosker JP, Rudenski AS, et al. Homeostasis model assessment: insulin resistance and beta cell function from plasma FBS and insulin concentrations in man. Diabetologia. 1985;28(7):412-419.

18. Carpagnano GE, Spanevello A, Sabato R, et al. Systemic and airway inflammation in sleep apnea and obesity: the role of ICAM-1 and IL-8. Transl Res. 2010;155(1):35-43.

19. Aukrust P, Yndestad A, Smith C, et al. Chemokines in cardiovascular risk prediction. Thromb Haemost. 2007;97(5): 748-754.

20. Charakida M, Masi S, Lüscher TF, et al. Assessment of atherosclerosis: the role of flow-mediated dilatation. Eur Heart J. 2010;31(23):28542861 .

21. VK Vijayan. Morbidities associated with obstructive sleep apnea. Expert Rev Respir Med. 2012;6(5):557-566.

22. Morgenstern M, Wang J, Beatty N, et al. Greenberg, Obstructive sleep apnea: an unexpected cause of insulin resistance and diabetes. Endocrinol Metab Clin N Am. 2014;43(1):187-204.

23. Hirotsu C, Albuquerque RG, Nogueira H, et al. The relationship between sleep apnea, metabolic dysfunction and inflammation: The gender influence. Brain Behav Immun. 2007;59:211-218.

24. Ryan S, Taylor CT, Mc Nicholas WT. Predictors of elevated nuclear factor kappa B-dependent genes in obstructive sleep apnea syndrome. Am J Respir Crit Care Med. 2006;174(7):824-830.

25. Ciftci TU, Kokturk O, Bukan N, et al. The relationship between serum cytokine levels with obesity and obstructive sleep apnea syndrome. Cytokine. 2004;28(2):87-91.

26. Minoguchi K, Tazaki T, Yokoe T, et al. Elevated production of tumor necrosis factor-alpha by monocytes in patients with obstructive sleep apnea syndrome. Chest. 2004;126(5):1473-1479.

27. Bhushan B, Guleria R, Misra A, et al. TNF-alpha gene polymorphism and TNF-alpha levels in obese Asian Indians with obstructive sleep apnea. Respir Med. 2009;103(3):386-392.

28. Dorkova Z, Petrasova D, Molcanyiova A, et al. Effects of continuous positive airway pressure on cardiovascular risk profile in patients with severe obstructive sleep apnea and metabolic syndrome. Chest. 2008;134(4):686-692.

29. Arias MA, García-Río F, Alonso-Fernández A, et al. CPAP decreases plasma levels of soluble tumour necrosis factor-alpha receptor 1 in obstructive sleep apnoea. Eur Respir J. 2008;32(4):1009-1015.

30. Dyugovskaya L, Lavie P, Lavie L. Phenotypic and functional characterization of blood gamma delta $\mathrm{T}$ cells in sleep apnea. $A m \mathrm{~J}$ Respir Crit Care Med. 2003;168(2):242-249.

31. Ohga E, Tomita T, Wada H, et al. Effects of obstructive sleep apnea on circulating ICAM-1 IL-8, and MCP-1. J Appl Physiol. 2003;94(1):179. 184.

32. Ryan S, Taylor CT, McNicholas WT. Predictors of elevated nuclear factorkappaB- dependent genes in obstructive sleep apnea syndrome. Am J Respir Crit Care Med. 2006;174(7):824-830.

33. Devouassoux G, Lévy P, Rossini E, et al. Sleep apnea is associated with bronchial inflammation and continuous positive airway pressure-induced airway hyperresponsiveness. J Allergy Clin Immunol. 2007;119(3):597603.

34. Arnardottir ES, Mackiewicz M, Gislason T, et al. Molecular signatures of obstructive sleep apnea in adults: a review and perspective. Sleep. 2009;32(4):447-470. 
35. Arnardottir ES, Maislin G, Schwab RJ, et al. The interaction of obstructive sleep apnea and obesity on the inflammatory markers C-reactive protein and interleukin-6: the Icelandic sleep apnea cohort. Sleep. 2012;35(7):921-932.

36. Vgontzas AN, Papanicolaou DA, Bixler EO, et al. Sleep apnea and daytime sleepiness and fatigue: relation to visceral obesity, insulin resistance, and hypercytokinemia. J Clin Endocrinol Metab. 2000;85(3):1151-1158.

37. Montesi S, Bajwa E, Malhotra A. Biomarkers of sleep apnea. Chest 2012;142(1):239-245.

38. Reyad E, Abdelaty N, ElPrince M, et al. Plasma levels of TNF in obstructive sleep apnea syndrome (OSA) before and after surgical intervention. Egyptian Journal of Chest Diseases and Tuberculosis. 2012;61:s179-s185.

39. Minoguchi K, Yokoe T, Tazaki T, et al. Increased carotid intima-media thickness and serum inflammatory markers in obstructive sleep apnea. Am J Respir Crit Care Med. 2005;172(5):625-630.

40. Yokoe T, Minoguchi K, Matsuo H, et al. Elevated levels of C-reactive protein and interleukin-6 in patients with obstructive sleep apnea syndrome are decreased by nasal continuous positive airway pressure. Circulation. 2003;107(8):1129-1134.

41. Zamarrón-Sanz C, Ricoy-Galbaldon J, Gude-Sampedro F, et al. Plasma levels of vascular endothelial markers in obstructive sleep apnea. Arch Med Res. 2006;37(4):552-555.
42. O Korzh, S Krasnokutskiy, E Lavrova. Role of low-grade inflammation markers and soluble cell adhesion molecules in patients with obstructive sleep apnea. Sleep Medicine. 2007;8(Suppl 1):S69-S114.

43. Priou P, Gagnadoux F, Tesse A, et al. Endothelial dysfunction and circulating microparticles from patients with obstructive sleep apnea. Am J Pathol. 2010;177(2):974-983.

44. Ohga E, Nagase T, Tomita T, et al. Increased levels of circulating ICAM1, VCAM-1, and L-selectin in obstructive sleep apnea syndrome. $J$ Appl Physiol. 1999;87(1):10-14.

45. El-Solh AA, Mador MJ, Sikka P, et al. Adhesion molecules in patients with coronary artery disease and moderate-to-severe obstructive sleep apnea. Chest. 2002;121(5):1541-1547.

46. Ursavaş A, Karadağ M, Rodoplu E, et al. Circulating ICAM-1 and VCAM-1 levels in patients with obstructive sleep apnea syndrome. Respiration. 2007;74(5):525-532.

47. Ip MS, Lam B, Ng MM, et al. Obstructive sleep apnoea is independently associated with insulin resistance. Am J Respir Crit Care Med. 2002;165(5):670-671.

48. Fleming WE, Ferouz-Colborn A, Samoszuk MK et al. Blood biomarkers of endocrine, immune, inflammatory, and metabolic systems in obstructive sleep apnea. Clin Biochem. 2016;49(12):854-861. 